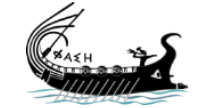

journal.phaselis.org

\title{
Phaselis Antik Kenti ve Beydağları (Olympos) Sahil Milli Parkının Kuşları
}

The Birds of Phaselis Ancient City and Beydağları (Olympos) Coastal National Park

\author{
Mehmet Rızvan TUNÇ
}

The entire contents of this journal, Phaselis: Journal of Interdisciplinary Mediterranean Studies, is open to users and it is an 'open access' journal. Users are able to read the full texts, to download, to copy, print and distribute without obtaining the permission of the editor and author(s). However, all references to the articles published in the e-journal Phaselis are to indicate through reference the source of the citation from this journal.

Phaselis: Journal of Interdisciplinary Mediterranean Studies is a peer-reviewed journal and the articles which have had their peer reviewing process completed will be published on the web-site (journal.phaselis.org) in the year of the journal's issue (e.g. Volume II: JanuaryDecember 2016). At the end of December 2016 the year's issue is completed and Volume III: January-December 2017 will begin.

Responsibility for the articles published in this journal remains with the authors.

Citation M. R. Tunç, "Phaselis Antik Kenti ve Beydağları (Olympos) Sahil Milli Parkının Kuşları". Phaselis III (2017) 297-314. http://dx.doi.org/10.18367/Pha.17018

Received Date: 22.09.2017 | Acceptance Date: 28.11.2017 | Online Publication Date: 26.12.2017

Editing Phaselis Research Project www.phaselis.org 


\title{
Phaselis Antik Kenti ve Beydağları (Olympos) Sahil Milli Parkının Kuşları

\author{
The Birds of Phaselis Ancient City and Beydağları (Olympos) Coastal National Park
}

\author{
Mehmet Rızvan TUNÇ*
}

\begin{abstract}
Öz: Beydağları (Olympos) Sahil Milli Parkı ve Phaselis Antik Kentinde 2012 yılından itibaren yapılan çalışmalarla Antalya ve çevresinin yaklaşık 20 yıldır yapılan çalışmaları birleştirilerek yayılış gösteren ornitofauna türleri değerlendirilmiştir. Phaselis Antik Kenti ve Bey Dağları (Olympos) Sahil Milli Parkı 2012 yılından bu yana periyodik olarak daha detaylı çalışıımışır. Bu çalışmalar sonucunda 54 familyaya ait 199 tür tespit edilmiştir. Alanda yaşayan bu türlerden 91'i non passeres, 108'i passeres türüdür. Bu türlerin 69'u yerli, 73'ü yaz göçmeni, 26'sı transit göçer, 31'i kış göçmenidir. Bu türlerin koruma statüleri nonpasseres'ten; 2 tür NT, 2 tür VU, 87 tür LC kategorisinde, passeres'ten; 2 tür NT ve 106 tür LC kategorisinde, yer alır.
\end{abstract}

Anahtar sözcükler: Phaselis, Olympos, Beydağları, Kuş, Biyoçeşitlilik, Antalya

Abstract: In the Beydağları (Olympos) Coastal National Park and the Phaselis Antique City, studies on ornitofauna were carried out since the year of 2012, with the works of Antalya and its surroundings being combined for about 20 years. Phaselis Ancient City and Bey Dağları (Olympos) Coastal National Park has been worked in more detail since 2012. Finally, 199 species belonging to 54 families were identified as the result of these studies. Of these species living in the area, 91 are non passeres and 108 are passeres. 69 of these species are native, 73 are summer migrants, 26 are transit migrants, and 31 are winter migrants. The conservation status of these species is from nonpassers; 2 species of NT, 2 of VU, 87 of LC, passeres; There are 2 species of NT and 106 of LC.

Keywords: Phaselis, Olympos, Beydağları, Bird, Biodiversity, Antalya

\section{Giriş}

Türkiye, Avrupa, Asya ve Afrika kıtaları arasında köprü konumunda olması nedeniyle, hayvan türleri ve özellikle kuşlar için çok önemli yaşamsal bir ekosistem bütünlüğü oluşturmaktadır ${ }^{1}$. Sahip olduğu sulak alan, orman, mera ve bozkır özelliğindeki ekosistem zenginliği, kuş türleri için önemli yaşam alanlarını oluşturmuştur². Avrupa'nın farklı ülkelerinde üreyen kuş türlerinin bazıları Anadolu'nun ılıman güney bölgelerinde kışlarken, önemli sayıdaki kuş populasyonları göçleri sırasında başta İstanbul Boğazı olmak üzere Marmara Bölgesi'nde, doğuda ise Kafkasya'dan Artvin, Borçka ve Çoruh vadisini izleyerek güney bölgelerine ve özellikle binlerce kuş Hatay ve Belen üzerinden Afrika'ya yol alır. Ayrıca, başta bıldırcın olmak üzere kuzeyden Karadeniz'i aşıp Anadolu'ya geçen kuş türleri Anadolu'nun kuzey bölgelerinden başlayarak cephe göçü yapar. Bu ve diğer tüm göçmen türler için göç esnasında kullanacakları enerjinin kaynağı olan ve belirli

\footnotetext{
Uzman, Akdeniz Üniversitesi, Fen Fakültesi, Biyoloji Bölümü, 07058, Antalya. rtunc@akdeniz.edu.tr Demirsoy 1999.

2 Kiziroğlu 2008.
} 
süre dinlendikleri konaklama alanları büyük önem taşımaktadır. Göçmen kuşlar, ilkbahar ve sonbahar göç dönemlerinde zamanlarının büyük kısmını bu konaklama alanlarında geçirirler. Anadolu'nun iklimsel ve topoğrafik yapısı da canlı çeşitliliğinin artışında en önemli etkenlerdendir. Türkiye'nin bu göç yolları üzerinde olmasından dolayı Kiziroğlu tarafından yapılan en son değerlendirmelere göre Türkiye'de 437 kuş türünün düzenli ve 65 türün düzensiz olmak üzere toplam 502 kuş türü yayılış göstermektedir³. Bu durum Avrupa'daki 533 (BirdLife International 2015) kuş türüne bakıldığında türlerin büyük bir kısmının Türkiye'de de yayııı̧ göstermesi Anadolu'nun önemini daha da arttırmaktadır.

Gelişmiş omurgalı hayvanlar içerisinde havadaki yaşama ilk olarak adapte olan sınıf Aves (Kuşlar) kara ve hava arasındaki etkileşimden en çok etkilenen hayvanlardır. Bu sayede yeryüzünde havadan ulaşımın mümkün olduğu her yere, deniz kenarlarından okyanuslara, yüksek dağ zirvelerinden balta girmemiş ormanlara, çöllerden kutuplara kadar çok çeşitli habitatlara yayılmışlardır. Ülkemizde de karasal ve sucul ekosistemlerin hemen hemen tamamında rastlanılabilen kuşlar birçok araştırmacı ve gözlemci için ilgi odağı konumundadırlar. Bu bakımdan ülkemizin çeşitli yerlerinde muhtelif zamanlarda yapılmış çok sayıda çalışma mevcuttur ${ }^{4}$. Yine birçok faunistik çalışmada ise diğer omurgalı gruplarıyla birlikte durumları değerlendirilen sınıflar olarak karşımıza çıkmaktadır ${ }^{5}$.

Antalya ve çevresinde 1995 yılından itibaren yapılan çalışmalarda 334 kuş türünün yayılış gösterdiği saptanmıştır ${ }^{6}$. Yapılan bu çalışmalarla bölgede yayılış gösteren bu kuşların tür listeleri, tehlike statüleri kırmıı listesi Red Data Book (RDB), Koruma durumları, Uluslararası Doğal Hayatı ve Doğal Kaynakları Koruma Birliği (IUCN Red List), Bern Sözleşmesi, Nesli Tehlike Altında Olan Yabani Hayvan ve Bitki Türlerinin Uluslararası Ticaretine Illişkin Sözleşme (CITES), Bird in Europa (BIE doğal populasyonlarının belirlenerek koruma alanlarının belirlenmesi) ölçütleri, statüleri ve yaşam alanları (Tablo 1)'de verilmiştir.

Antalya, Altınbeşik Mağarası, Beydağları (Olympos) Sahil, Köprülü Kanyon ve Termessos Milli Parkları olmak üzere 4 adet milli park ile ülkemizdeki en çok milli parka sahip ilimizdir. Ayrıca, Kurşunlu Şelalesi Tabiat Parkına sahiptir. Bu parklar toplam olarak 79.366 hektarlık alanı kaplamaktadır. Ülkemizde geniş ölçekte çalışılan, bilim insanlarının ve profesyonel/amatör kuş gözlemcilerinin ilgisini çeken kuşlarla ilgili olarak Beydağları (Olympos) Sahil Milliparkı ve Phaselis Antik Kenti Teritoryumu'nda spesifik olarak yapılmış güncel çalışmalar yetersizdir ${ }^{7}$. Bu bakımdan sahadaki kuş varlığını irdeleyen yoğun ornitolojik çalışmalara ihtiyaç duyulmaktadır. Bu ihtiyacı gidermek için bu çalışmada sahanın ornitofaunistik durumu irdelenmiş ve sahanın mevcut durumu ile ilgili güncel bilgiler verilmiştir.

\footnotetext{
Kiziroğlu 2008.

4 Detaylı bilgi için bk. Baran - Yılmaz 1984; Kiziroğlu 1987; 1989; Martins 1989; Jonsson 1992; Kiziroğlu et al. 1992; Roselaar 1995; Heinzel et al. 1996; Yarar et al. 1997; Kirwan et al. 1998; Mullarney 1999; Heath et al. 2000; 2001; Kiziroğlu 2009; Swensson et al. 2010.

5 Detaylı bilgi için bk. Erdoğan - Tunç 1998; Turan et al. 1998; Erdoğan et al. 2004; Düşen et al. 2005; Erdoğan et al. 2008; 2010; Yavuz - Tunç 2015a; 2015b.

6 Erdoğan et al. 2002; 2003; Sert - Erdoğan 2004; Karaardıç et al. 2006; 2007; Erdoğan et al. 2010; Yavuz Tunç 2015a; Karaardıç et al. 2016.

7 Yavuz - Tunç 2015a.
} 


\section{Materyal ve Metot}

Beydağları (Olympos) Sahil Milli Parkı 31.018 hektarlık alanı ile Antalya ilinde yer alan en geniş yüzölçümüne sahip Milli Parktır. Beydağları (Olympos) Sahil Milliparkı 36³5'42.56" K 30³0'32.86" D enlem ve boylamları arasında Antalya limanından başlayıp Adrasan burnunun ucuna kadar yaklaşık $90 \mathrm{~km}$ sahil bandında Kumluca ve Kemer ilçelerinin sınırları içerisinde yer alır. Phaselis antik kenti ise Antalya'ya $50 \mathrm{~km}$ mesafede kemer ilçesinin sınırları içerisinde yer alır. Beydağları (Olympos) Sahil Milli Parkı Antik Likya bölgesinde yer almaktadır (Fig. 1). Kızılçam ormanları denizle birlikte başlar 1000-1200 metreye kadar. 1000 metreden sonra sedir ve karaçam, 1800 metreden itibaren ardıç ormaları başlamaktadır. Böyle bir ekolojik çeşitliliğe engebeli ve sarp kayalıklara sahip olmasından

dolayı zengin fauna ve flora yapısına sahiptir.

Beydağları (Olympos) Sahil Milli Parkı ve Phaselis Antik Kentinde 2012-2017 yılları arasında yapılan çalışmalarla daha önce Antalya ve çevresinde yapılan yaklaşık 20 yıllık çalışmalar ile birleştirilerek yayılış gösteren ornitofauna türleri değerlendirilmiştir. Çalışma alanındaki kuşlar yaşam ortamlarında, su içlerinde, kumsalda, ormanda ve çalılık alanlarda gözlenmiş, fotoğraflanmış ve kuşların çoğu görsel yolla, gözle görülemeyen az bir bölümü de ötüşlerinden teşhis edilmiş̧ir. Bu anlamda kuş türlerinin tespiti için, alan bazında bölge değerlendirilmiş, dürbün, teleobjektifli fotoğraf makinesi ve video kamera kullanılarak kuş türleri belirlenmeye çalışılmışır. Ayrıca yöre halkı ile görüşmeler yapılarak alanı kullanan kuş türleri ve göç hareketleri ile ilgili bilgi alışverişi de yapılmıştır. Kuşların tespiti için hat

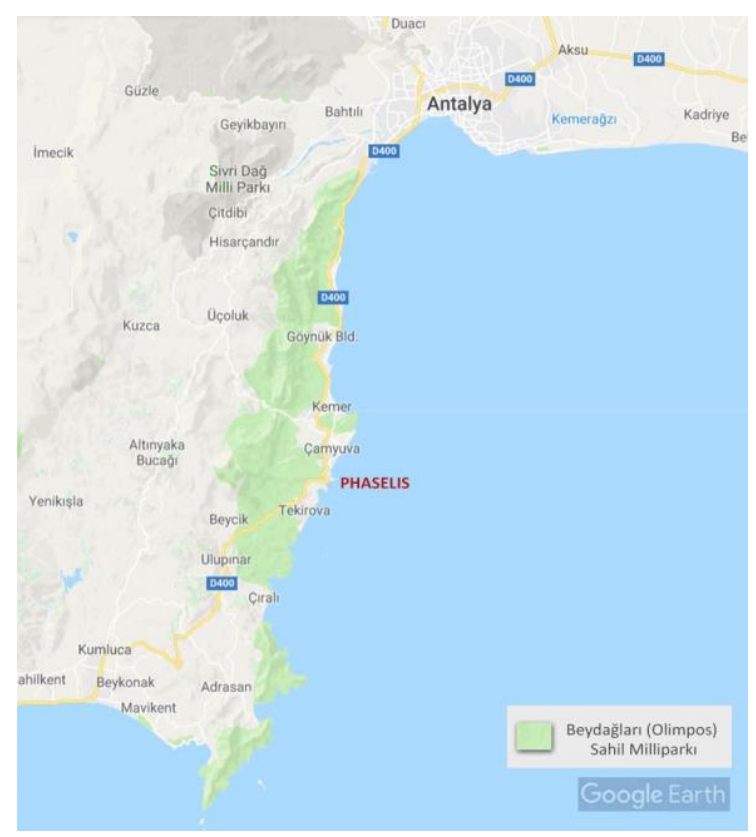

Fig. 1. Beydağları (Olympos) Sahil Milliparkı ve Phaselis Antik Kentinin Lokalizasyonu boyunca (transekt), rastgele gözlem ve nokta gözlem uygulamaları yapılmıştır. Tespit edilen kuş türlerinin familya ve bilimsel isimleri, Türkçe adları, biyotopları (habitat), varsa tehlike kategorisi, tehlike sınıfı açısından değerlendirmesi, statüleri ile ilgili veriler değerlendirilmiştir. Bu amaçla Türkiye kuş türlerinin statüleri kırmızı listesi Red Data Book (RDB), IUCN; The International Union for Conservation of Nature (Red List Statüleri tüm Avrupa statüleride verilmiştir.), Bern Sözleşmesi kriterleri ve koruma listelerinin en son güncellenmiş halleri; CITES (Tehlike Altında Olan Yabani Hayvan ve Bitki Türlerinin Uluslararası Ticaretine Iliş̧kin Sözleşme); Bird in Europa (BIE doğal populasyonlarının belirlenerek koruma alanlarının belirlenmesi) ölçütlerinden de yararlanılmışıı. Diğer taraftan yörenin faunası havza bazında ele alınmış, tablolarda sahada bulunabilecek türlere de yer verilmiştir. Bunlara ek olarak yörede kaydedilen yabanıl formlar arasında endemik türler bulunup bulunmadığı da değerlendirilmiştir.

\section{Bulgular}

Beydağları (Olympos) Sahil Milli Parkında ve Phaselis Antik Kentinde 2012 yılından itibaren periyodik olarak yapılan arazi çalışmaları ile geçmiş dönemlerde yürütülen gözlem ve araştırmalarda elde edilen bilimsel verilerden de yararlanılmıştır. Yapılan gözlem, inceleme ve 
değerlendirme sonucunda çalışma alanı ve yakın çevresinde Non-passeres'ten 26 familyaya ait 91 tür, Passerres grubundan 28 familyaya ait 108 tür olmak üzere 54 familyaya ait 199 tür saptanmıştır. Bu türlerden 69'u yerli (Y), 73'ü yaz göçmeni (YG), 31'i kış göçmeni (KG), 26'sı transit göçer (TG)'dir. Bölgede yayılış gösteren türlerden 13'ü nonpasseres 11'i passeres grubunda bulunan 24 tür Türkiye Kuşları Kırmızı Listesin'de (RDB) A1.2 kriterinde olup, bu kriterde yer alan türlerin nüfusları Türkiye genelinde çok azalmıştır. İzlendikleri bölgelerde 1 birey-10 çift (=1-20 birey) ile temsil edilirler. Bu türlerin soyu büyük ölçüde tükenme tehdidi altında olduğu için, Türkiye genelinde mutlaka korunmaları gereken türlerdir. Ayrıca 50 tür A.2 kriterinde tükenme baskısı günümüzdeki gibi devam ederse mutlak tükenmeyle karşı karşıya kalacak olan türlerdir.

Beydağları (Olympos) Sahil Milliparkı ve Phaselis Antik Kentinde yayılı̧ gösteren kuş türlerinin ulusal ve uluslararası koruma durumları ile bölgesel statüleri Çizelge $1^{\prime}$ de değerlendirilmiştir. Bu değerlendirmeler Türkiye Kuşları Kırmızı Listesi ${ }^{8}$, Uluslararası Doğal Hayatı ve Doğal Kaynakları Koruma Birliği (IUCN), Bern sözleşmesi Ek Listesi, Nesli Tehlike Altında Olan Yabani Hayvan ve Bitki Türlerinin Uluslararası Ticaretine Iliş̧kin Sözleşmesi (CITES) Ek Listelerine göre yapılmıştır.

Beydağları (Olympos) Sahil Milliparkı ve Phaselis Antik Kenti'nin kuşları Türkiye'deki türlerin şimdilik yaklaşık \%20'ni oluştururken ileriki yıllarda yapılacak arazi çalışmalarıyla görülen tür sayısında değişikler de olabilecektir. Bölgede yaşayan kuş türlerine ait bazı türlerin fotoğrafları, betimlemeleriyle birlikte aşağıda (Figs. 2-5) verilmiştir. Türlerin özellikleri verilirken ve betimlemeleri yapılırken bazı kaynaklardan yararlanılmışır ${ }^{9}$.

Sahada bulunan kuş türlerinden bazıları fotoğraf ve betimlemeleriyle birlikte aşağıda verilmiştir:

\section{Anas platyrhynchos (Linnaeaus 1758) Yeşilbaş Ördek}

Boyu 50-60 cm kanat açıkığı 81-95 cm arasındadır. Erkek ve dişi farklı görünüşe sahip olup üreme formu yoktur. Yaygın olan bir ördek türüdür. Doğal ortamlar dışında 29 yıl yaşadığı saptanmıştır. Genel olarak bütün sulak alanlarda yaşar. Yapay olarak oluşturulmuş küçük göletlerde de evcil olarak beslenmektedir. Çeşitli bitkiler, yosunlar ve hayvansal besinler ile beslenirler. Tüm Yurdumuzda üremektedir. Yerli ve yaz göçmenidir. Tüm Türkiye de bulunur. Bu tür Phaselis Antik kenti yakınlarında bulunan ve ilerideki çalışmalarda yeniden canlandırılması düşünülen

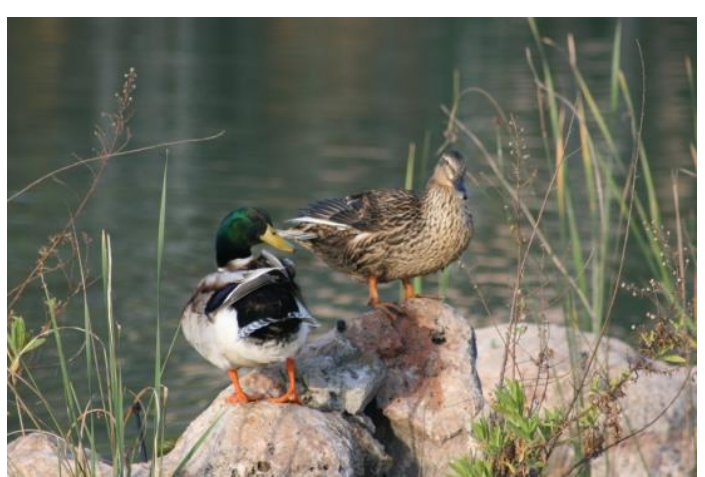

Fig. 2. Antik kent içindeki Phaselis göletinde görülebilen yeşilbaş ördek Phaselis göletinde devamlı olarak görülebilir. Avrupa'nın tamamında Hazar Denizi'nin batısı ve Akdeniz sahil şeridinde yayılış gösterir. Bern sözleşmesine göre koruma altında olan bir türdür. Avlanılmasına belli dönemlerde izin verilir (Fig. 2).

\footnotetext{
Kiziroğlu 2008.
}

Mullarney 1999; Bird Life International 2004a; Erdoğan et al. 2004; Düşen et al. 2005, IUCN 2006; Erdoğan et al. 2010; Anonim 2013a; IUCN 2013; IUCN 2015-4, IUCN 2017-2. 
Tablo 1. Sahada bulanan kuş türlerin; Familya, Bilimsel isimleri, Türkçe isimleri, İngilizce isimleri ve ile Koruma durumları; Uluslararası Doğal Hayatı ve Doğal Kaynakları Koruma Birliği (IUCN Red List), Bern Sözleşmesi Koruma Statüleri, Türkiye kuşları kırmızı listesi (RDB), Bird in Europa (BiE doğal populasyonlarının belirlenerek koruma alanlarının belirlenmesi) ölçütleri, Nesli Tehlike Altında Olan Yabani Hayvan ve Bitki Türlerinin Uluslararası Ticaretine Iliş̧kin Sözleşme (CITES), bölgedeki statüleri ve yaşam alanları aşağıda verilmiştir.

\begin{tabular}{|c|c|c|c|c|c|c|c|c|c|c|}
\hline Familya & Latince Adı & Türkçe Adı & Ingilizce Adı & Bern & $\begin{array}{c}\text { Stat } \\
\text { ü }\end{array}$ & $\mathrm{RDB}$ & $\mathrm{BIE}$ & \begin{tabular}{|l|} 
IUCN \\
Red \\
list \\
status \\
\end{tabular} & CITES & $\begin{array}{r}\text { Yaşam } \\
\text { Alanı }\end{array}$ \\
\hline \multicolumn{11}{|l|}{ NON PASSERES } \\
\hline \multirow{3}{*}{ PODICIPEDIDAE } & Tachybaptus ruficollis & Küçük Batağan & Little Grebe & Ekll & $\bar{Y}$ & A.3.1 & $\mathrm{V}$ & LC & $\overline{--}$ & $\mathrm{S}$ \\
\hline & Podiceps cristatus & Tepeli Batağan & Great Crested Grebe & EkIIII & $\mathrm{Y}$ & A.5 & $\mathrm{V}$ & LC & -- & $\mathrm{S}$ \\
\hline & Podiceps nigricollis & Karaboyun Batağan & Black-necked Grebe & EkII & KG & A. 4 & $\mathrm{~V}$ & LC & -- & $\mathrm{s}$ \\
\hline PROCELLARIIDAE & Puffinus yelkovan & Yelkovan & Yelkouan Shearwater & Ekll & $\bar{Y}$ & A.5 & -- & $\mathrm{VU}$ & - & $\mathrm{S}$ \\
\hline PHALACROCORACIDAE & Phalacrocorax carbo & Karabatak & Great Cormorant & EkIII & $\mathrm{KG}$ & A.3 & $\mathrm{V}$ & LC & - & $S$ \\
\hline \multirow{9}{*}{ ARDEIDAE } & Botaurus stellaris & Balaban & Eurasian Bittern & Ekll & $\mathrm{YG}$ & A.3.1 & III & $\mathrm{LC}$ & -- & $S$ \\
\hline & Ixobrychus minutus & Cüce Balaban & CommonLittle Bittern & Ekll & YG & A.2 & III & LC & - & $S$ \\
\hline & Nycticorax nycticorax & Gece Balıkçılı & $\begin{array}{l}\text { Black-crowned Night- } \\
\text { heron }\end{array}$ & Ekll & YG & A.3.1 & III & LC & - & $S$ \\
\hline & Ardeola ralloides & Alaca Balıkçıl & Squacco Heron & Ekll & $\mathrm{YG}$ & A.3 & III & LC & - & $S$ \\
\hline & Bubulcus ibis & Öküz Balıkçıl & Cattle Egret & Ekll & YG & A.2 & $\mathrm{V}$ & LC & -- & $\mathrm{s}$ \\
\hline & Egretta garzetta & Küçük Akbalıkçıl & Little Egret & Ekll & $\mathrm{Y}$ & A.3.1 & $\mathrm{V}$ & LC & -- & $\mathrm{S}$ \\
\hline & Ardea alba & Büyük Akbalıkçıl & Great white Egret & Ekll & $\mathrm{YG}$ & A.3 & $\mathrm{V}$ & LC & - & $S$ \\
\hline & Ardea cinerea & Gri Balıkçıl & Grey Heron & EkIIII & $Y$ & A.3.1 & $\mathrm{V}$ & LC & -- & $S$ \\
\hline & Ardea purpurea & Erguvani Balıkçıl & Purple Heron & Ekll & $\mathrm{YG}$ & A.2 & III & $\mathrm{LC}$ & -- & $S$ \\
\hline CICONIIDAE & Ciconia ciconia & Ak leylek & White Stork & Ekll & $\mathrm{YG}$ & A.3.1 & $\|$ & LC & -- & $S, T$ \\
\hline \multirow{2}{*}{ THRESKIORNITHIDAE } & Plegadis falcinellus & Çeltikçi & Glossy Ibis & Ekll & TG & A.3.1 & III & LC & -- & $S$ \\
\hline & Platalea leucorodia & Kaşıkçı & Eurasian Spoonbil & Ekll & TG & A.3 & II & LC & -- & $\mathrm{s}$ \\
\hline
\end{tabular}




\begin{tabular}{|c|c|c|c|c|c|c|c|c|c|c|}
\hline Familya & Latince Adı & Türkçe Adı & Ingilizce Adı & Bern & $\begin{array}{l}\text { Stat } \\
\text { ü }\end{array}$ & RDB & $\mathrm{BIE}$ & $\begin{array}{l}\text { IUCN } \\
\text { Red } \\
\text { list } \\
\text { status }\end{array}$ & CITES & $\begin{array}{c}\text { Yaşam } \\
\text { Alanı }\end{array}$ \\
\hline \multirow{4}{*}{ ANATIDAE } & Anas strepera & Boz Ördek & Gadwall & EkIII & KG & A.4 & III & LC & -- & $S$ \\
\hline & Anas crecca & Çamurcun & Common Teal & EkIII & KG & A.5 & V & LC & -- & $S$ \\
\hline & Anas querquedula & Çıkrıkçın & Garganey & EkIII & KG & A.4 & III & LC & -- & $\mathrm{S}$ \\
\hline & Anas platyrhynchos & Yeşilbaş Ördek & Mallard & EkIII & Y & A.5 & IV & LC & -- & $\mathrm{S}$ \\
\hline \multirow{10}{*}{ ACCIPITRIDAE } & Pernis apivorus & Arı Şahini & European Honey-buzzard & EkIII & YG & A.3 & IV & LC & Ekll & $\mathrm{O}, \mathrm{M}, \mathrm{T}$ \\
\hline & Circaetus gallicus & Yılan Kartalı & Short-toed Snake-eagle & EkII & YG & A.4 & III & LC & EkII & $\mathrm{T}, \mathrm{K}, \mathrm{O}$ \\
\hline & Clanga pomarina & Küçük Orman Kartalı & Lesser Spotted Eagle & Ekll & TG & A.3 & II & LC & Ekll & $\mathrm{O}, \mathrm{K}$ \\
\hline & Aquila chrysaetos & Kaya Kartalı & Golden Eagle & Ekll & $Y$ & A.1.2 & III & LC & EkII & $\mathrm{K}$ \\
\hline & Milvus migrans & Kara Çaylak & Black Kite & Ekll & KG & A.3 & III & LC & Ekll & $\mathrm{O}, \mathrm{C}, \mathrm{K}$ \\
\hline & Circus aeruginosus & Saz Delicesi & Western Marsh-harrier & EkII & $\bar{Y}$ & A.3 & IV & LC & Ekll & $S$ \\
\hline & Circus cyaneus & Gökçe Delice & Northern Harrier & EkII & KG & A.1.2 & III & LC & EkII & $\mathrm{M}, \mathrm{S}$ \\
\hline & Accipiter nisus & Atmaca & Eurasian Sparrowhawk & EkII & $\mathrm{Y}$ & A.3 & IV & LC & EkII & $\mathrm{O}$ \\
\hline & Buteo buteo & Şahin & Common Buzzard & Ekll & KG & A.3 & IV & LC & Ekll & $\mathrm{O}$ \\
\hline & Buteo rufinus & Kızıl Şahin & Long-legged Buzzard & EkII & YG & A.3 & II & LC & EkII & 0 \\
\hline \multirow{4}{*}{ FALCONIDAE } & Falco tinnunculus & Kerkenez & Common Kestel & Ekll & $Y$ & A.2 & III & LC & Ekll & $\mathrm{M}, \mathrm{T}, \mathrm{O}$ \\
\hline & Falco eleonorae & Ada Doğanı & Eleonora's Falcon & Ekll & YG & A.1.2 & II & LC & Ekll & $\mathrm{O}, \mathrm{M}, \mathrm{K}$ \\
\hline & Falco subbuteo & Delice Doğan & Eurasian Hobby & Ekll & YG & A.3.1 & IV & LC & Ekll & $\mathrm{O}, \mathrm{M}, \mathrm{K}$ \\
\hline & Falco peregrinus & Gökgoğan & Peregrine Falcon & EkII & YG & A.1.2 & IV & $\mathrm{LC}$ & Ekl & $\mathrm{O}, \mathrm{M}, \mathrm{K}$ \\
\hline \multirow{2}{*}{ PHASIANIDAE } & Coturnix coturnix & Bıldırcın & Common Quail & EkIII & YG & A.3 & III & LC & -- & $\mathrm{M}, \mathrm{T}$ \\
\hline & Alectoris chukar & Kınalı Keklik & Chukar & EkIII & $Y$ & A.2 & III & LC & -- & $\mathrm{M}, \mathrm{K}$ \\
\hline \multirow{3}{*}{ RALLIDAE } & Rallus aquaticus & Su Yelvesi & Western Water Rail & EkIII & $\mathrm{TG}$ & A.3 & IV & LC & -- & $S$ \\
\hline & Porzana porzana & Benekli su Yelvesi & Spotted Crake & EkII & TG & A.2 & IV & LC & -- & $S$ \\
\hline & Zapornia parva & Benekli Küçük su Yelvesi & Little Crake & Ekll & TG & A.1.2 & IV & LC & -- & $S$ \\
\hline
\end{tabular}




\begin{tabular}{|c|c|c|c|c|c|c|c|c|c|c|}
\hline Familya & Latince Adı & Türkçe Adı & İngilizce Adı & Bern & $\begin{array}{c}\text { Stat } \\
\text { ü }\end{array}$ & RDB & $\mathrm{BIE}$ & $\begin{array}{l}\text { IUCN } \\
\text { Red } \\
\text { list } \\
\text { status } \\
\end{array}$ & CITES & $\begin{array}{l}\text { Yaşam } \\
\text { Alanı }\end{array}$ \\
\hline & Zapornia pusilla & Cüce su Yelvesi & Baillon's Crake & Ekll & TG & A.1.2 & III & LC & -- & S \\
\hline & Crex crex & Bıldırcın Kılavuzu & Corncrake & Ekll & TG & A.1.2 & I & LC & -- & S \\
\hline & Gallinula chloropus & Yeşilayak Sutavuğu & Common Moorhen & EkIII & Y & A.3.1 & IV & LC & -- & S \\
\hline & Fulica atra & Sakar Meke & Coomon Coot & EkIII & Y & A. 5 & IV & LC & -- & $\mathrm{S}$ \\
\hline \multirow{2}{*}{ RECURVIROSTRIDAE } & Himantopus himantopus & Uzunbacak & Black-winged Stilt & Ekll & YG & A.3 & IV & LC & -- & S \\
\hline & Recurvirostra avosetta & Kılıçgaga & Pied Avocet & Ekll & YG & A.4 & IV & LC & -- & $\mathrm{S}$ \\
\hline BURHINIDAE & Burhinus oedicnemus & Kocagöz & Eurasian Thick-knee & Ekll & YG & A. 2 & III & LC & -- & $\mathrm{S}, \mathrm{M}, \mathrm{T}$ \\
\hline \multirow{4}{*}{ CHARADRIIDAE } & Charadrius dubius & Kolyeli Küçük Yağmur Kuşu & Little Ringed Plover & Ekll & YG & A.3 & IV & LC & -- & $S$ \\
\hline & Charadrius hiaticula & Kolyeli Büyük Yağmur Kuşu & Common Ringed Plover & Ekll & YG & B.3 & IV & LC & -- & S \\
\hline & Charadrius alexandrinus & Kesik Kolyeli Yağmur Kuşu & Kentish Plover & Ekll & YG & A.4 & III & LC & -- & S \\
\hline & Vanellus vanellus & Kız Kuşu & Northern Lapwing & EkIII & TG & A.5 & ॥ & LC & -- & S \\
\hline \multirow{10}{*}{ SCOLOPACIDAE } & Calidris minuta & Küçük Kumkuşu & Little Stint & Ekll & KG & B.5 & IV & LC & -- & $\mathrm{S}$ \\
\hline & Calidris temminckii & Sarıbacak Kumkuşu & Temminck's Stint & Ekll & TG & B.3 & IV & LC & -- & $\mathrm{S}$ \\
\hline & Calidris ferruginea & Kızılkumkuşu & Curlew Sandpiper & Ekll & KG & B.4 & -- & NT & -- & S \\
\hline & Calidris pugnax & Döğüşkekuş & Ruff & EkIII & TG & B.4 & ॥ & LC & -- & S \\
\hline & Gallinago gallinago & Suçulluğu & Common Snipe & EkIII & KG & B.3.1 & III & LC & -- & $\mathrm{S}$ \\
\hline & Scolopax rusticola & Çulluk & Eurasian Woodcock & EkIII & KG & B.3 & III & LC & -- & $S$ \\
\hline & Limosa limosa & Karakuyruk su çulluğu & Black-tailed Godwit & EkIII & KG & B.4 & II & NT & -- & $\mathrm{S}$ \\
\hline & Tringa totanus & Kızılbacak & Common Redshank & EkIII & YG & A.4 & II & LC & -- & $\mathrm{S}$ \\
\hline & Tringa glareola & Orman Kızılbacağı & Wood Sandpiper & Ekll & TG & B.3 & III & LC & -- & $\mathrm{O}$ \\
\hline & Actitis hypoleucos & Dere düdükçünü & Common Sandpiper & Ekll & YG & A.3 & III & LC & -- & $\mathrm{S}, \mathrm{M}$ \\
\hline \multirow[b]{2}{*}{ LARIDAE } & Larus melanocephalus & Akdeniz Martısı & Mediterranean Gull & Ekll & Y & A.3.1 & IV & LC & -- & $S$ \\
\hline & Hydrocoloeus minutus & Cüce Martı & Little Gull & Ekll & $K G$ & B.3 & III & LC & -- & $\mathrm{S}$ \\
\hline
\end{tabular}




\begin{tabular}{|c|c|c|c|c|c|c|c|c|c|c|}
\hline \multirow[t]{6}{*}{ Familya } & Latince Adı & Türkçe Adı & Ingilizce Adı & Bern & $\begin{array}{c}\text { Stat } \\
\ddot{u}\end{array}$ & RDB & BIE & \begin{tabular}{|l|} 
IUCN \\
Red \\
list \\
status \\
\end{tabular} & CITES & $\begin{array}{c}\text { Yaşam } \\
\text { Alanı }\end{array}$ \\
\hline & Larus ridibundus & Karabaş Martı & Black-headed Gull & Ekll & Y & A.5 & IV & LC & -- & $S$ \\
\hline & Larus michahellis & Gümüşi Martı & Yellov-Legged Gull & EkIII & $Y$ & A.4 & $\|$ & LC & -- & $S$ \\
\hline & Sterna hirundo & Sumru & Common Tern & Ekll & $\mathrm{TG}$ & A.3 & IV & LC & -- & $S$ \\
\hline & Chlidonias hybrida & Akbıyık Deniz Kırlangıcı & Whiskered Tern & EkII & $\bar{Y}$ & A.3 & III & LC & -- & $S$ \\
\hline & Chlidonias leucopterus & Akkanatlı Sumru & White-winged Tern & EkII & $\bar{Y}$ & A.4 & IV & LC & -- & $S$ \\
\hline \multirow{5}{*}{ COLUMBIDAE } & Columba livia & Kaya Güvercini & Rock Dove & EKIII & Y & A.5 & IV & LC & -- & $\mathrm{K}, \mathrm{O}$ \\
\hline & Columba palumbus & Tahtalı & Common Wood-pigeon & EkIII & $Y$ & A.4 & IV & LC & -- & $\mathrm{O}$ \\
\hline & Streptopelia decaocto & Kumru & Eurasian Collared-dove & EkIII & $\bar{Y}$ & A.5 & IV & LC & -- & $0, T$ \\
\hline & Streptopelia turtur & Üveyik & European Turtle-dove & EkIII & YG & A.3.1 & III & VU & -- & $\mathrm{O}$ \\
\hline & Spilopelia senegalensis & Küçük Kumru & Laughing Dove & EkIII & Y & A.4 & IV & LC & -- & $\mathrm{Y}$ \\
\hline CUCULIDAE & Cuculus canorus & Gugukkuşu & Common Cuckoo & EkIII & YG & A.2 & IV & LC & -- & $\mathrm{O}$ \\
\hline TYTONIDAE & Tyto alba & Peçeli Baykuş & Common Barn-owl & EkII & Y & A.1.2 & III & LC & Ekll & 0 \\
\hline \multirow{5}{*}{ STRIGIDAE } & Athene noctua & Kukumav & Little owl & Ekll & Y & A.2 & III & LC & EkII & $O, Y$ \\
\hline & Otus scops & Ishak kuşu & Eurasian Scops-owl & Ekll & YG & A.2 & $\|$ & LC & EkII & $O, Y$ \\
\hline & Bubo bubo & Puhu kuşu & Eurasian Eagle-owl & Ekll & Y & A.1.2 & III & LC & EkII & $O, Y$ \\
\hline & Strix aluco & Alaca Baykuş & Tawny Owl & Ekll & Y & A.2 & IV & LC & Ekll & $0, T$ \\
\hline & Asio otus & Kulaklı Orman Baykuşu & Northern Long-eared Owl & Ekll & Y & A.2 & IV & LC & EkII & $0, T$ \\
\hline CAPRIMULGIDAE & Caprimulgus europaeus & Çobanaldatan & Eurasian Nightjar & EkII & YG & A.1.2 & $\|$ & LC & -- & $\mathrm{O}, \mathrm{M}, \mathrm{T}$ \\
\hline \multirow{2}{*}{ APODIDAE } & Apus apus & Kara Sağan & Common Swift & EkIII & YG & A.3.1 & IV & LC & -- & $U, Y$ \\
\hline & Tachymarptis melba & Ak karınlı Sağan & Alpine Swift & Ekll & $Y G$ & A.3.1 & IV & LC & -- & $U, Y$ \\
\hline ALCEDINIDAE & Alcedo atthis & Yalı Çapkını & Common Kingfisher & EkII & $Y$ & A.2 & III & LC & -- & $S$ \\
\hline MEROPIDAE & Merops apiaster & Arıkuşu & European Bee-eater & Ekll & TG & A.3.1 & III & LC & -- & $\mathrm{M}, \mathrm{T}, \mathrm{U}$ \\
\hline CORACIIDAE & Coracias garrulus & Gökkuzgun & European Roller & Ekll & YG & A. 2 & II & LC & -- & $\mathrm{O}, \mathrm{T}, \mathrm{M}$ \\
\hline
\end{tabular}




\begin{tabular}{|c|c|c|c|c|c|c|c|c|c|c|}
\hline Familya & Latince Adı & Türkçe Adı & İngilizce Adı & Bern & $\begin{array}{c}\text { Stat } \\
\text { ü }\end{array}$ & RDB & $\mathrm{BIE}$ & $\begin{array}{l}\text { IUCN } \\
\text { Red } \\
\text { list } \\
\text { status } \\
\end{array}$ & CITES & $\begin{array}{l}\text { Yaşam } \\
\text { Alanı }\end{array}$ \\
\hline UPUPIDAE & Upupa eрорs & Çavuşkuşu & Common Hoopoe & Ekll & YG & A. 2 & III & LC & -- & $\mathrm{T}, \mathrm{M}$ \\
\hline \multirow{4}{*}{ PICIDAE } & Jynx torquilla & Boyunçeviren & Eurasian Wryneck & Ekll & YG & A.1.2 & III & LC & -- & $\mathrm{O}, \mathrm{M}$ \\
\hline & Dendrocopos syriacus & Alaca Ağaçkakan & Syrian Woodpecker & Ekll & Y & A. 2 & IV & LC & -- & $\mathrm{O}, \mathrm{T}, \mathrm{Y}$ \\
\hline & Leiopicus medius & Albaş Ağaçkakan & Middle Spotted Woodpecker & Ekll & Y & A.1.2 & IV & LC & -- & $0, T$ \\
\hline & Dryobates minor & Küçük Ağaçkakan & Lesser Spotted Woodpecker & Ekll & Y & A.1.2 & IV & LC & -- & $0, T$ \\
\hline \multicolumn{11}{|l|}{ PASSERES } \\
\hline \multirow{6}{*}{ ALAUDIDAE } & Melanocorypha calandra & Boğmaklı Tarla Kuşu & Calandra Lark & Ekll & YG & A. 5 & III & LC & -- & MK \\
\hline & Calandrella brachydactyla & Bozkır Toygarı & Greater Short-toed Lark & Ekll & YG & A.3 & III & LC & -- & T \\
\hline & Galerida cristata & Tepeli Toygar & Crested Lark & EkIII & Y & A.3 & III & LC & -- & $\mathrm{M}, \mathrm{T}$ \\
\hline & Lullula arborea & Orman Toygarı & Wood Lark & EkIII & Y & A.3 & ॥ & LC & -- & $\mathrm{O}, \mathrm{M}$ \\
\hline & Alauda arvensis & Tarla Kuşu & Eurasian Skylark & EkIII & YG & A.4 & III & LC & -- & OM \\
\hline & Eremophila alpestris & Kulaklı Tarla Kuşu & Horned Lark & Ekll & Y & A.3.1 & IV & LC & -- & K \\
\hline \multirow{5}{*}{ HIRUNDINIDAE } & Riparia riparia & Kum KırlangıCı & Collared Sand Martin & Ekll & YG & A. 5 & III & LC & -- & $\mathrm{S}, \mathrm{T}, \mathrm{U}$ \\
\hline & Ptyonoprogne(Hirundo)rupestris & Kaya kırlangıcı & Eurasian Crag-martin & Ekll & YG & A.5 & IV & LC & -- & K \\
\hline & Hirundo rustica & Kır Kırlangıcı & Barn Swallow & Ekll & YG & A.5 & III & LC & -- & $\mathrm{Y}, \mathrm{M}, \mathrm{T}$ \\
\hline & Cecropis daurica & Kızıl Sırtlı Kırlangıç & Red-rumped Swallow & Ekll & YG & A.3 & IV & LC & -- & $\mathrm{K}, \mathrm{T}, \mathrm{M}$ \\
\hline & Delichon urbicum & Ev Kırlangıcı & Northern House-martin & Ekll & YG & A.3 & III & LC & -- & Y \\
\hline \multirow{6}{*}{ MOTACILLIDAE } & Anthus trivialis & Ağaç İncirkuşu & Tree Pipit & Ekll & TG & A.3 & IV & LC & -- & $\mathrm{O}, \mathrm{M}$ \\
\hline & Anthus pratensis & Çayır İncirkuşu & Meadow Pipit & Ekll & TG & A. 3 & IV & NT & -- & M \\
\hline & Anthus cervinus & Algerdan İncirkuşu & Red-throated Pipit & Ekll & TG & A. 2 & IV & LC & -- & $\mathrm{M}, \mathrm{T}$ \\
\hline & Anthus spinoletta & Dağ İncirkuşu & Water Pipit & Ekll & TG & A. 3 & IV & LC & -- & $\mathrm{O}, \mathrm{K}$ \\
\hline & Motacilla flava & Sarıkuyruksallayan & Yellow Wagtail & Ekll & YG & A.3.1 & IV & LC & -- & $\mathrm{T}, \mathrm{M}$ \\
\hline & Motacilla cinerea & Dağ Kuyrukkakanı & Grey Wagtail & Ekll & Y & A. 2 & IV & LC & -- & $\mathrm{K}, \mathrm{O}, \mathrm{M}$ \\
\hline
\end{tabular}




\begin{tabular}{|c|c|c|c|c|c|c|c|c|c|c|}
\hline Familya & Latince Adı & Türkçe Adı & İngilizce Adı & Bern & $\begin{array}{c}\text { Stat } \\
\ddot{u}\end{array}$ & RDB & BIE & $\begin{array}{l}\text { IUCN } \\
\text { Red } \\
\text { list } \\
\text { status }\end{array}$ & CITES & $\begin{array}{c}\text { Yaşam } \\
\text { Alanı }\end{array}$ \\
\hline & Motacilla alba & Akkuyruksallayan & White Wagtail & Ekll & Y & A.3.1 & IV & LC & -- & $\mathrm{T}, \mathrm{M}$ \\
\hline PYCNONOTIDAE & Pycnonotus xanthopygos & Arap Bülbülü & White-spectacled Bulbul & Ekll & Y & A.2 & IV & LC & -- & O.T \\
\hline CINCLIDAE & Cinclus cinclus & Derekuşu & White-throated Dipper & Ekll & Y & A.1.2 & IV & LC & -- & $S$ \\
\hline TROGLODYTIDAE & Troglodytes troglodytes & Çitkuşu & Winter Wren & EkII & Y & A.1.2 & IV & LC & -- & $\mathrm{M}, \mathrm{T}$ \\
\hline PRUNELLIDAE & Prunella modularis & Çit Serçesi & Hedge Accentor & Ekll & KG & A.1.2 & IV & LC & -- & $\mathrm{K}, \mathrm{O}$ \\
\hline \multirow{18}{*}{ MUSCICAPIDAE } & Erithacus rubecula & Kızılgerdan & European Robin & Ekll & KG & A.3 & IV & LC & -- & $\mathrm{M}, \mathrm{O}, \mathrm{T}, \mathrm{Y}$ \\
\hline & Cercotrichas galactotes & Kızıl Çalıbülbülü & Rufous-tailed Scrub-robin & Ekll & YG & A.3 & III & LC & -- & $\mathrm{M}, \mathrm{O}, \mathrm{T}$ \\
\hline & Luscinia megarhynchos & Bülbül & Common Nightingale & Ekll & YG & A.2 & IV & LC & -- & $\mathrm{M}, \mathrm{O}$ \\
\hline & Luscinia luscinia & Alacagöğüs Bülbül & Thrush Nightingale & Ekll & $\mathrm{TG}$ & A.2 & IV & LC & -- & $\mathrm{M}, \mathrm{O}$ \\
\hline & Cyanecula svecica & Buğdaycıl & Bluethroat & Ekll & YG & A.2 & IV & LC & -- & $\mathrm{M}, \mathrm{K}, \mathrm{O}$ \\
\hline & Irania gutturalis & Taş Bülbülü & White-throated Robin & Ekll & $\mathrm{Y}$ & A.1.2 & IV & LC & -- & $\mathrm{M}, \mathrm{K}$ \\
\hline & Phoenicurus ochruros & Kara Kızılkuyruk & Black Redstart & Ekll & KG & A.2 & IV & LC & -- & $\mathrm{M}, \mathrm{O}, \mathrm{Y}$ \\
\hline & Phoenicurus phoenicurus & Kızılkuyruk & Common Redstart & Ekll & YG & A.3 & $\|$ & LC & -- & $\mathrm{M}, \mathrm{O}, \mathrm{Y}$ \\
\hline & Saxicola rubetra & Çayır Taşkuşu & Whinchat & Ekll & YG & A.3 & IV & LC & -- & $\mathrm{M}, \mathrm{O}, \mathrm{T}, \mathrm{Y}$ \\
\hline & Saxicola torquatus & Taşkuşu & Common Stonechat & Ekll & KG & A.3 & IV & LC & -- & $\mathrm{K}, \mathrm{M}, \mathrm{T}$ \\
\hline & Oenanthe isabellina & Toprak Renkli Kuyrukkakan & Isabelline Wheatear & Ekll & YG & A.3 & IV & LC & -- & $\mathrm{K}, \mathrm{T}$ \\
\hline & Oenanthe oenanthe & Kuyrukkakan & Northern Wheatear & Ekll & YG & A.3 & III & LC & -- & $\mathrm{K}, \mathrm{O}$ \\
\hline & Oenanthe finschii & Kaya Kuyrukkakanı & Finsch's Wheatear & Ekll & YG & A.1.2 & IV & LC & -- & K \\
\hline & Oenanthe hispanica & Karakulaklı Kuyrukkakan & Black-eared Wheatear & Ekll & YG & A.2 & II & LC & -- & $\mathrm{Y}, \mathrm{T}, \mathrm{M}, \mathrm{O}$ \\
\hline & Oenanthe pleschanka & Alaca Kuyrukkakan & Pied Wheatea & Ekll & TG & A.1.2 & IV & LC & -- & K \\
\hline & Monticola saxatilis & Kaya Ardıcı & Rufous-tailed Rock-thrush & Ekll & YG & A.1.2 & III & LC & -- & K \\
\hline & Monticola solitarius & Mavi Kaya Ardıcı & Blue Rock-thrush & Ekll & Y & A.1.2 & III & LC & -- & K \\
\hline & Muscicapa striata & Gri sinekkapan & Spotted Flycatcher & Ekll & YG & A.3 & III & LC & -- & $\mathrm{O}, \mathrm{M}$ \\
\hline
\end{tabular}




\begin{tabular}{|c|c|c|c|c|c|c|c|c|c|c|}
\hline Familya & Latince Adı & Türkçe Adı & Ingilizce Adı & Bern & $\begin{array}{c}\text { Stat } \\
\ddot{u}\end{array}$ & RDB & BIE & \begin{tabular}{|l|} 
IUCN \\
Red \\
list \\
status
\end{tabular} & CITES & $\begin{array}{c}\text { Yaşam } \\
\text { Alanı }\end{array}$ \\
\hline & Ficedula albicollis & Halkalı Sinekkapan & Collared Flycatcher & Ekll & TG & A. 2 & IV & LC & -- & $\mathrm{O}, \mathrm{M}$ \\
\hline & Ficedula semitorquata & Yarımband Sinekkapan & Semi-collared Flycatcher & Ekll & TG & A.3 & II & LC & -- & $\mathrm{M}, \mathrm{O}$ \\
\hline \multirow{4}{*}{ TURDIDAE } & Turdus merula & Karatavuk & Eurasian Blackbird & EkIII & $\mathrm{Y}$ & A.3 & IV & LC & -- & $\mathrm{Y}, \mathrm{O}, \mathrm{M}$ \\
\hline & Turdus iliacus & Kızıl Ardıç & Redwing & EkIII & KG & B. 2 & IV & NT & -- & $\mathrm{O}, \mathrm{M}$ \\
\hline & Turdus philomelos & Öterardıç & Song Thrush & EkIII & KG & A.2 & IV & LC & -- & $\mathrm{O}$ \\
\hline & Turdus viscivorus & Ökseotu Ardıcı & Mistle Thrush & EkIII & KG & A. 2 & IV & LC & -- & $\mathrm{O}, \mathrm{K}$ \\
\hline SCOTOCERCIDAE & Cettia cetti & Kamış Bülbülü & Cetti's Warbler & Ekll & Y & A. 2 & IV & LC & -- & $\mathrm{S}, \mathrm{M}$ \\
\hline LOCUSTELLIDAE & Locustella luscinioides & Bataklık Kamışçını & Savi's Warbler & Ekll & YG & A.2 & IV & LC & -- & $\mathrm{S}, \mathrm{M}$ \\
\hline \multirow{6}{*}{ ACROCEPHALIDAE } & Acrocephalus melanopogon & Bıyıklı Kamışcın & Moustached Warbler & Ekll & YG & A.2 & IV & LC & -- & S \\
\hline & Acrocephalus schoenobaenus & Kındıra Kamışçını & Sedge Warbler & Ekll & TG & A.2 & IV & LC & -- & S \\
\hline & Acrocephalus scirpaceus & Saz Bülbülü & Common Reed-warbler & Ekll & YG & A.2 & IV & LC & -- & $S$ \\
\hline & Acrocephalus arundinaceus & Büyük Kamışcın & Great Reed-warbler & Ekll & YG & A.3 & IV & LC & -- & $S$ \\
\hline & Iduna pallida & Gri Mukalit & Eastern Olivaceous Warbler & Ekll & YG & A.3 & III & LC & -- & $\mathrm{M}, \mathrm{O}$ \\
\hline & Hippolais olivetorum & Zeytin Mukalidi & Olive-tree Warbler & Ekll & YG & A. 2 & IV & LC & -- & $\mathrm{M}, \mathrm{O}$ \\
\hline \multirow{8}{*}{ SYLVIDAE } & Sylvia cantillans & Aksakal Ötleğen & Subalpine Warbler & Ekll & YG & A.2 & IV & LC & -- & $\mathrm{M}, \mathrm{O}$ \\
\hline & Sylvia melanocephala & Karabaş Küçük ötleğen & Sardinian Warbler & Ekll & $\mathrm{Y}$ & A.3 & IV & LC & -- & $M, Y$ \\
\hline & Sylvia nisoria & Çizgili Ötleğen & Barred Warbler & Ekll & YG & A. 2 & IV & LC & -- & $\mathrm{M}, \mathrm{O}$ \\
\hline & Sylvia rueppelli & Aksakal Ötleğen & Rueppell's Warbler & Ekll & YG & A.2 & IV & LC & -- & $\mathrm{M}, \mathrm{O}$ \\
\hline & Sylvia curruca & Akgerdan Ötleğen & Lesser Whitethroat & Ekll & YG & A. 2 & IV & LC & -- & $M, Y$ \\
\hline & Sylvia borin & Boz Ötleğen & Garden Warbler & Ekll & TG & B. 3 & IV & LC & -- & $\mathrm{O}, \mathrm{M}$ \\
\hline & Sylvia communis & Akgerdanlı Ötleğen & Common Whitethroat & Ekll & YG & A.3 & IV & LC & -- & $\mathrm{O}, \mathrm{M}$ \\
\hline & Sylvia atricapilla & Karabaş Ötleğen & Blackcap & Ekll & YG & A. 2 & IV & LC & -- & $M, Y, O$ \\
\hline CISTICOLIDAE & Prinia gracilis & Çizgili Ötleğen & Graceful Prinia & EkIII & Y & A.3 & III & LC & -- & $\mathrm{T}, \mathrm{M}$ \\
\hline
\end{tabular}




\begin{tabular}{|c|c|c|c|c|c|c|c|c|c|c|}
\hline Familya & Latince Adı & Türkçe Adı & Ingilizce Adı & Bern & $\begin{array}{c}\text { Stat } \\
\ddot{u}\end{array}$ & RDB & BIE & $\begin{array}{l}\text { IUCN } \\
\text { Red } \\
\text { list } \\
\text { status }\end{array}$ & CITES & $\begin{array}{c}\text { Yaşam } \\
\text { Alanı }\end{array}$ \\
\hline \multirow{3}{*}{ PHYLLOSCOPIDAE } & Phylloscopus sibilatrix & Orman Söğüt Bülbülü & Wood Warbler & EKII & TG & A.2 & $\|$ & LC & -- & $\mathrm{O}$ \\
\hline & Phylloscopus collybita & Çıvgın & Common Chiffchaff & EKII & $\bar{Y}$ & A.3.1 & IV & LC & -- & $\mathrm{O}, \mathrm{M}, \mathrm{Y}$ \\
\hline & Phylloscopus trochilus & Söğüt Bülbülü & Willow Warbler & EKII & TG & A.3.1 & IV & LC & -- & $\mathrm{O}$ \\
\hline REGULIIDAE & Regulus regulus & Altıntavukçuk & Goldcrest & Ekll & $Y$ & A.1.2 & IV & LC & -- & $\mathrm{O}, \mathrm{M}$ \\
\hline AEGITHALIDAE & Aegithalos caudatus & Uzunkuyruk Baştankara & Long-tailed Tit & EkIII & $Y$ & A.2 & IV & LC & -- & $\mathrm{O}$ \\
\hline \multirow{4}{*}{ PARIDAE } & Poecile lugubris & Akyanak Baştankara & Sombre Tit & Ekll & Y & A.2 & IV & LC & -- & $\mathrm{O}$ \\
\hline & Periparus ater & Çam Baştankarası & Coal Tit & Ekll & $Y$ & A.3 & IV & LC & -- & $\mathrm{O}$ \\
\hline & Cyanistes caeruleus & Mavi Baştankara & Eurasian Blue Tit & Ekll & $Y$ & A.2 & IV & LC & -- & $\mathrm{O}$ \\
\hline & Parus major & Büyük Baştankara & Great Tit & Ekll & Y & A.3.1 & IV & LC & -- & $O, Y$ \\
\hline \multirow{3}{*}{ SITTIDAE } & Sitta krueperi & Anadolu Sıvacısı & Krueper's Nuthatch & Ekll & Y & A.2 & $\|$ & LC & -- & $\mathrm{O}$ \\
\hline & Sitta neumayer & Kaya Sıvacısı & Western Rock-nuthatch & Ekll & Y & A.2 & IV & LC & -- & K \\
\hline & Sitta europaea & Sivacı & Eurasian Nuthatch & Ekll & Y & A.3 & IV & LC & & $\mathrm{O}$ \\
\hline \multirow{2}{*}{ CERTHIIDAE } & Certhia brachydactyla & Bahçe Tırmaşı̆̆ı & Short-toed Treecreeper & Ekll & Y & A.1.2 & IV & LC & -- & $\mathrm{O}$ \\
\hline & Certhia familiaris & Ağaç Tırmaşığı & Eurasian Treecreeper & Ekll & Y & A.1.2 & IV & LC & -- & $\mathrm{O}$ \\
\hline ORIOLIDAE & Oriolus oriolus & Sarıasma & Eurasian Golden Oriole & Ekll & YG & A.2 & IV & LC & -- & $O, Y$ \\
\hline \multirow{4}{*}{ LANIIDAE } & Lanius collurio & Kızılsırtlı Örümcekkuşu & Red-backed Shrike & Ekll & YG & A.3 & III & LC & -- & $\mathrm{O}, \mathrm{M}, \mathrm{T}, \mathrm{Y}$ \\
\hline & Lanius senator & Kızılbaşlı Örümcekkuşu & Woodchat Shrike & EkII & YG & A. 2 & $\|$ & LC & -- & $\mathrm{O}, \mathrm{M}, \mathrm{T}$ \\
\hline & Lanius minor & Klara Alın Örümcekkuşu & Lesser Grey Shrike & Ekll & YG & A.3 & II & LC & -- & $\mathrm{T}, \mathrm{M}, \mathrm{O}$ \\
\hline & Lanius nubicus & Maskeli Örümcekkuşu & Masked Shrike & Ekll & YG & A.2 & $\|$ & LC & -- & $\mathrm{O}, \mathrm{M}$ \\
\hline \multirow{4}{*}{ CORVIDAE } & Garrulus glandarius & Alakarga & Eurasian Jay & EkIII & $Y$ & A.3.1 & IV & LC & -- & 0 \\
\hline & Pyrrhocorax pyrrhocorax & Sarıgaga Dağ Kargası & Red-billed Chough & Ekll & Y & A.3 & III & LC & -- & $\mathrm{K}, \mathrm{O}$ \\
\hline & Pyrrhocorax graculus & Kızılgaga Dağ Kargası & Yellow-billed Chough & Ekll & Y & A.3 & IV & LC & -- & $\mathrm{K}, \mathrm{O}$ \\
\hline & Corvus corone & Leş Kargası & Carrion Crow & EkIII & $Y$ & A. 5 & IV & LC & -- & $\mathrm{Y}, \mathrm{T}, \mathrm{O}$ \\
\hline
\end{tabular}




\begin{tabular}{|c|c|c|c|c|c|c|c|c|c|c|}
\hline Familya & Latince Adı & Türkçe Adı & İngilizce Adı & Bern & $\begin{array}{l}\text { Stat } \\
\text { ü }\end{array}$ & RDB & BIE & \begin{tabular}{|l|} 
IUCN \\
Red \\
list \\
status \\
\end{tabular} & CITES & $\begin{array}{c}\text { Yaşam } \\
\text { Alanı }\end{array}$ \\
\hline & Corvus corax & Kuzgun & Common Raven & EkIII & Y & A.5 & IV & LC & -- & K \\
\hline STURNIDAE & Sturnus vulgaris & Sığırcık & Common Starling & Ekll & KG & A.5 & III & LC & -- & $\mathrm{Y}, \mathrm{T}, \mathrm{M}$ \\
\hline \multirow{4}{*}{ PASSERIDAE } & Passer domesticus & Ev Serçesi & House Sparrow & EkIII & Y & A.5 & III & LC & -- & $\mathrm{Y}, \mathrm{M}, \mathrm{T}, \mathrm{S}$ \\
\hline & Passer hispaniolensis & Bataklık Serçesi & Spanish Sparrow & EkIII & YG & A.3 & IV & LC & -- & S \\
\hline & Petronia petronia & Kayalık Şerçesi & Rock Sparrow & Ekll & KG & A.3 & IV & LC & -- & $\mathrm{K}, \mathrm{O}$ \\
\hline & Montifringilla nivalis & Kar İspinozu & White-winged Snowfinch & Ekll & KG & A.2 & IV & LC & -- & K \\
\hline \multirow{10}{*}{ FRINGILLIDAE } & Fringilla coelebs & İspinoz & Eurasian Chaffinch & EkIII & Y & A.4 & IV & LC & -- & $\mathrm{O}, \mathrm{Y}, \mathrm{M}, \mathrm{T}$ \\
\hline & Fringilla montifringilla & Dağ İspinozu & Brambling & EkIII & KG & A.4 & IV & LC & -- & $\mathrm{O}, \mathrm{K}, \mathrm{T}$ \\
\hline & Serinus pusillus & Kızılalın İskete & Fire-fronted Serin & Ekll & Y & A.3 & IV & LC & -- & $\mathrm{K}, \mathrm{O}$ \\
\hline & Serinus serinus & Kanarya & European Serin & Ekll & KG & A.3 & IV & LC & -- & $\mathrm{O}, \mathrm{Y}, \mathrm{M}, \mathrm{T}$ \\
\hline & Spinus spinus & Karabaş İskete & Eurasian Siskin & Ekll & KG & A.3 & IV & LC & -- & $\mathrm{K}, \mathrm{M}$ \\
\hline & Carduelis chloris & Florya & European Greenfinch & EkII & $Y$ & A.3 & IV & LC & -- & $\mathrm{O}, \mathrm{M}, \mathrm{Y}, \mathrm{T}$ \\
\hline & Carduelis carduelis & Saka & European Goldfinch & Ekll & Y & A.3.1 & IV & LC & -- & $\mathrm{O}, \mathrm{M}, \mathrm{Y}, \mathrm{T}$ \\
\hline & Carduelis cannabina & Ketenkuşu & Eurasian Linnet & EkIII & Y & A.3 & II & LC & -- & $M, K, T$ \\
\hline & Rhodopechys sanguineus & Alamecek & Eurasian Crimson-winged Finch & EkIII & KG & A.3 & IV & LC & -- & K \\
\hline & Coccothraustes coccothraustes & Kocabaş & Hawfinch & Ekll & KG & A.3 & IV & LC & -- & $\mathrm{O}, \mathrm{M}$ \\
\hline \multirow{6}{*}{ EMBERIZIDAE } & Emberiza hortulana & Kirazkuşu & Ortolan Bunting & EkIII & YG & A.3 & $\|$ & LC & -- & K \\
\hline & Emberiza caesia & Kızıl Kirazkuşu & Cretzschmar's Bunting & Ekll & YG & A.2 & IV & LC & -- & $\mathrm{K}, \mathrm{O}, \mathrm{M}$ \\
\hline & Emberiza cia & Kaya Kirazkuşu & Rock Bunting & Ekll & KG & A.2 & III & LC & -- & K \\
\hline & Emberiza schoeniclus & Bataklık Kirazkuşu & Reed Bunting & Ekll & KG & A.3 & IV & LC & -- & S \\
\hline & Emberiza melanocephala & Karabaş Kirazkuşu & Black-headed Bunting & Ekll & YG & A.4 & IV & LC & -- & $\mathrm{M}, \mathrm{T}$ \\
\hline & Miliaria calandra & Tarla Kirazkuşu & Corn Bunting & EkIII & Y & A.4 & IV & LC & -- & $\mathrm{M}, \mathrm{T}$ \\
\hline
\end{tabular}

- Tür adı: Tür isimleri Latince, kuşların evrimsel skaladaki sırasına göre, ilkelden gelişmişe gidecek şekilde yazılmışır. 
Tabloda Kullanılan Kısaltmaların Açıklaması ve Değerlendirme Yaşam alanları

$\mathrm{S}=$ Sulak, batakık, kamışlık akarsu ve deniz kenarları. $\mathrm{O}=$ Orman ve ağaçlık alanlar.

$\mathrm{K}=$ Kayalık taşık ve step alanlar. $\quad M=$ Makilik, çalılık ve çayırlık alanlar.

$\mathrm{Y}=$ Yerleşim yerleri $\quad \mathrm{T}=$ Tarım alanları

$U=$ Uçarken

Statüleri

$Y=$ Yerli: Tüm yıl Türkiye'de yaşayan ve üreyen türler. Bunlardan 69 tür yerli.

YG= Yaz Göçmeni: Ilkbahar ve yaz aylarında Türkiye'ye gelerek üreyen türler. 73 tür yazın gelen türler.

KG= Kış Göçmeni: Kışın (Eylül-Mart) ayları arasında Türkiye'ye ve çalışma sahasına gelen türler. 31 tür kışın gelir.

TG= Transit Göçer: Türkiye'yi Illkbahar ve Sonbahar aylarında kısa bir süre ülkemizi kullanarak geçen türler. 26 tür beslenmek için ülkemizi kullanırlar.

\section{Erithacus rubecula( Linnaeus, 1758) Kızıl gerdan}

Boyu 12,5-14 cm kadardır. Erkek ve dişi aynı görünüşte olup üreme formu yoktur. Ormanlarda, parklarda, bahçelerde, çalılıklarda ve yerleşim alanlarında bulunurlar. Serin iklimlerde yaşarlar. Alanda hemen her yerde görülebilir. Ülkemizin iç Anadolu ve Doğu Anadolu'nun bazı kısımları hariç tamamında görülürler. Ülkemiz dışında Avrupa, İskandinav ülkeleri, Rusya'nın batısı, Kafkaslar, İran, Irak, Suriye, İsrail ve Kuzey Afrika ülkelerinde yayılış gösterirler. Bern sözleşmesine göre koruma altında olan bir türdür. Avlanılması yıl boyunca yasaktır (Fig. 3).

\section{Turdus merula (Linnaeus, 1758) Kara tavuk}

Boyu 23-29 cm arasındadır. Erkek ve dişi farklı görünüştedir. Üreme formu yoktur. Erkekleri özellikle üreme döneminde bazı kuşların ses taklitlerini yapabilirler. Ormanlık alanlarda, parklarda, bahçelerde, ağaçlıklı ve çalılıklı alanlarda yaşarlar. Böceklerle, solucanlarla, gasropodlarla ve meyvelerle beslenirler. Beslenmelerini genellikle sabahın erken saatlerinde yaparlar. Yurdumuzun tamamında kuluçkaya yatarlar. Yerli bir türdür. Bazı bölgeler için yaz göçmenidir. Yurdumuzun tamamında görülür. Türkiye dışında bütün Avrupa'da Kuzey Afrika'da, Suriye, Irak ve hazar

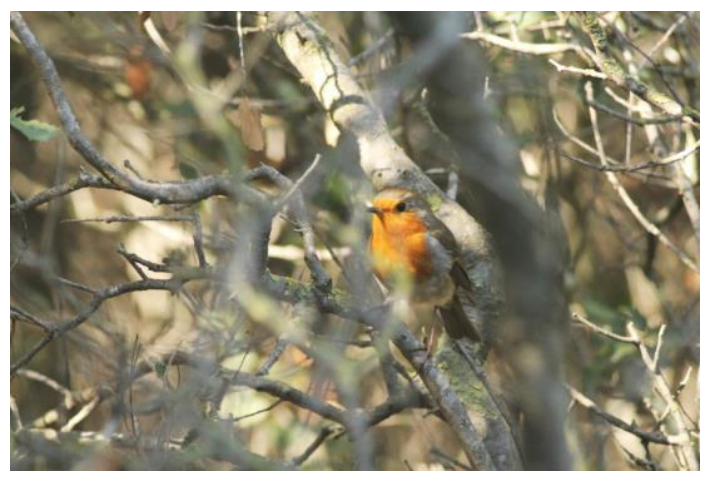

Fig. 3. Alanda hemen her yerde, çalılık ve ağaçlık alanlarda görülebilen kızıl gerdan

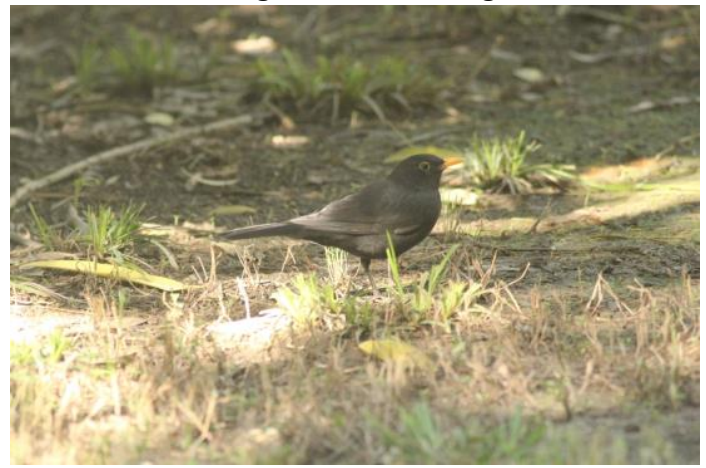

Fig. 4. Alanda çalılık, ve ormanlıklarda görülen Karatavuk (dişi birey), yuva için materyal taşırken Deniz'inin çevresinde yayılış gösterir. Bern sözleşmesine göre koruma altında olan bir türdür (Fig. 4).

\section{Acrocephalus arundinaceus (Linnaeus, 1758) Büyük kamışçın}

Boyu 16-20 cm arasındadır Kamış̧ınların en büyüğüdür. Erkek ve dişi aynı görünüşte olup üreme formu yoktur. Gagası ince uzun üstü koyu altı açık renklidir. Gaganın dip kısmından başlayıp gözün üstünden uzanan beyaz bir çizgi vardır. Karın kısmı kahverengimsi beyaz yan taraflar sarımsıdır. Baş üstü, kanat ve kuyruk üstü kahverengi, sırt ve kuyruk sokumu grimsi kahverengidir. Genellikle göller, bataklıklar ve sulak alanlardaki kamışlık ve sazlık alanlarda yaşarlar. Sazlık ve kamışların arasındaki böcekler ve larvalarıyla beslenirler. Akdeniz bölgesi, Ege, Karadeniz, Marmara 
ve iç Anadolu Bölgesinde kuluçkaya yatarlar. Bölgemiz için yaz göçmenidir. Bütün Türkiye'de görülür. Türkiye dışında bütün Avrupa'da, Güney Afrika'da yayılış gösterir. Bern sözleşmesine göre kesin koruma altında olan bir türdür. Avlanılması yıl boyunca yasaktır (Fig. 5).

\section{Tartışma ve Sonuç}

Bey Dağları (Olympos) Sahil Milliparkı ve Phaselis antik kenti coğrafik özelliği bakımında önem arz etmektedir. Deniz seviyesinden birden 2000 metreyi bulan dağlık ve sık ormanlık alanlardan dolayı zengin bir ekolojik yapıya sahiptir. Yaklaşık 1200 metreye kadar sık kızılçam ormanı ve

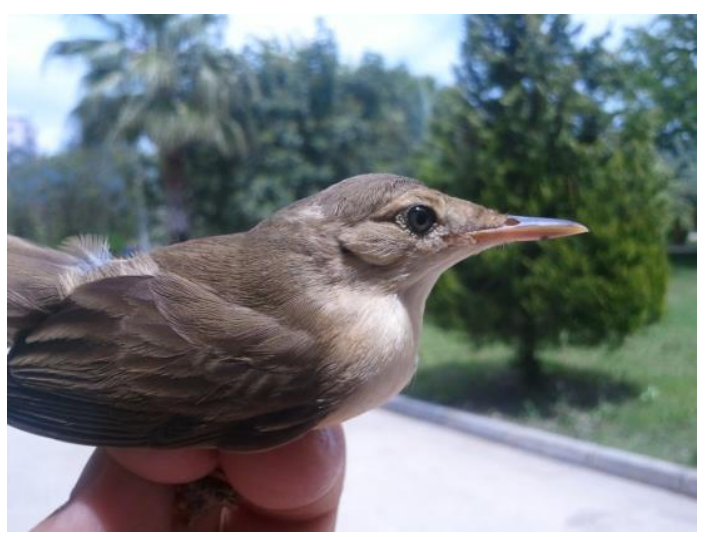

Fig. 5. Alandaki göletlerde ve sulak alanların kıyısındaki sazlıklarda görülebilen büyük kamışçın devamında 2000 metreye kadar sedir ve ardıç ağaçlarının bulunmasından dolayı zengin bir kuş habitatını barındırmaktadır. Beydağlarının dik ve sarp yamaçlarından ormanlık ve açıklık alanlarına kadar; geniş ve sık örtülü öbeklerinden, ormanaltı zonuna kadar ekolojik bir bütünlük arz etmektedir.

Bey Dağları (Olympos) Sahil Milliparkı coğrafik olarak dağlık ve ormanlık bir arazi yapısına sahip olması nedeniyle zengin bir tür çeşitliliğine sahiptir. Bu alanda yaşayan kuşlar bu dik yamaçları ve sık vegatasyonları barınma, sığınma, saklanma ve beslenme için ideal bir ortam olarak kullanmaktadırlar.

Yaz aylarında havanın sıcak olması nedeniyle orman yangınlarının sıkça yaşanması ve turizm bölgesi olduğu için sahil bandında yapılaşmanın yoğun olmasından dolayı ormanlık alanlar tahrip edilmekte olup, önlemler alınmazsa sadece ornitofauna değil memeli ve herpetofauna ve bitki türleride tehlike altına girecektir. Sahilden başlayan kızılçam ormanları, tarım alanları ve daha yükseklere çıktıkça değişen iklim ve bitki örtüsü sayesinde birçok ekolojik intiyaca cevap vermektedir. Saha mevcut habitat özellikleri, denizle karanın iç içe olduğu topografyası, kısmen sakin ortamı nedeniyle nispeten dar bir alanda çok sayıda türe ev sahipliği yapmaktadır. Türkiye'de yaşayan 502 kuş türü 199' bölgede yayılış göstermektedir ${ }^{10}$. Bölgede yayılış gösteren 24 tür Türkiye Kuşları Kırmızı Listesi'nde (RDB) A.1.2 Kriterinde olup, bu kriterde olan türlerin nüfusları Türkiye genelinde ciddi azalmalar göstermektedir. Bu türlerden Gökdoğan (Circus cyaneus), Ada doğanı (Falco eleonorae), Tyto alba (Peçeli Baykuş), Bubo bubo (Puhu kuşu), Çobanaldatan (Caprimulgus europaeus), Albaş Ağaçkakan (Leiopicus medius), Küçük Ağaçkakan (Dryobates minor) vb. gibi türlerin sayılarının azalması ormanlık alanlardaki azalmaya paralel olması ve bu türlerin bu tip alanlara ihtiyaç duyması gibi nedenlerden dolayı ön plana çıkmaktadır. Bu alanda son yıllarda yaşanan orman yangınları bu türlerin geleceğini tehdit etmektedir. Bu bakımdan sahadaki mevcut habitat ve biyotopların korunması ve geliştirilmesi büyük önem arz etmektedir. Bu alanların tahrip edilmesi, yaz aylarında sık rastlanılan orman yangınları ve çevrenin kirletilmesi nedeniyle biyolojik zenginliklerimiz zamanla yok olmaktadır. Bu da daha büyük tahribatlara yol açacaktır. Bölgenin korunması ve sürdürebilirliğinin sağlanması için bu alanlarda yaşayan insanların bilgilendirilmesi gerekmektedir. Zamanımızda az sayıda gördüğümüz ve görmeyi beklediğimiz türlerin (özellikle av hayvanlarının), bölgeye turizm gelmeden önce daha çok görüldüğü, çevre halkıyla yaptığımız görüşmelerle tespit edilmiştir.

10

Kiziroğlu 2009. 
Bu da gösteriyorki olumsuzluklar devam ettiği sürece nesli tehlike altında olan türlerin yoğunluğu gittikçe azalacaktır. Bunun en iyi örneğini Phaselis göleti oluşturmaktadır. Phaselis Antik Kentinde de Territoryumu içinde kuşlar olduğu kadar, tüm diğer fauna (Amfibi ve sürüngenler) elemanları için de büyük önem taşıyan Phaselis Göleti yer almaktadır (Fig. 6). Mevcut haliyle denizle ve başka tatlı su kaynaklarıyla bağlantısı kesilmiş olduğundan karasallaşmaya yüz tutmuş gölet, bu haliyle bile su kuşları ve bazı amfibiler için barınma, sığınma korunma ve beslenme ortamı oluşturmaktadır.

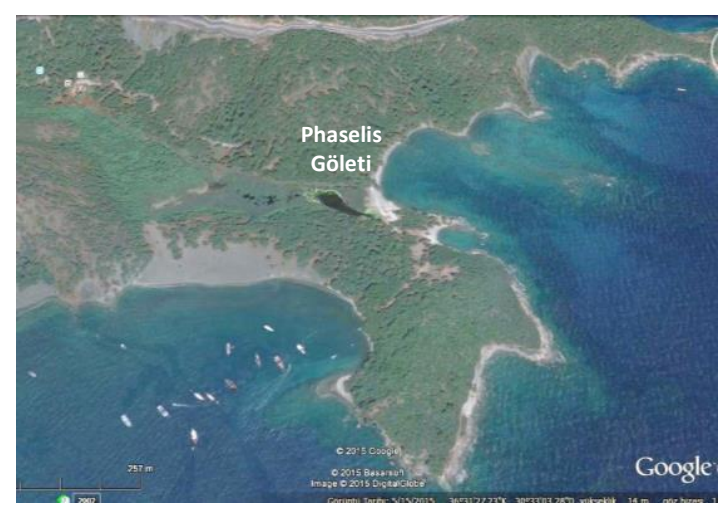

Fig. 6. Phaselis Göleti'nin konumunu gösteren uydu görüntüsü

Özellikle ıslah çalışmaları yapılarak yeniden eski canlılı̆ı ve limnetik özelliklerine yakın bir hale getirilebilirse hali hazırda var olan kuşlar için daha zengin ve temiz bir habitat sağlanmış olacaktır. 


\section{BIBBLIYOGRAFYA}

Anonim 2013

Baran - Yılmaz 1984

BirdLife International 2015

Demirsoy 1999

Düşen et al. 2005

Erdoğan - Tunç 1998

Erdoğan et al. 2002

Erdoğan et al. 2002

Erdoğan et al. 2002

Erdoğan et al. 2003

Erdoğan et al. 2004

Erdoğan et al. 2008

Erdoğan et al. 2010

Erdoğan et al. 2010

Heath et al. 2000

Heinzel et al. 1996

Heinzel et al. 2001

IUCN 2017-2

Jonsson 1992

Karaardıç et al. 2006

Karaardıç et al. 2007

Karaardıç et al. 2016
Anonim, TRAKUŞ (Türkiye'nin Anonim Kuşları). Kaynak: www.trakus.org i. Baran - I. Yılmaz, Ornitoloji Dersleri. İzmir 1984.

BirdLife International, European Red List of Birds. Luxembourg 2015. A. Demirsoy, "Genel ve Türkiye Zoocoğrafyası ve Hayvan Coğrafyası. Ankara 1999.

O. Düşen, M. R. Tunç, A. Aslan - H. B. Sert, "IX.I. Flora ve Fauna”. Eds. N. Çevik, B. Varkıvanç - E. Akyürek, Beydağları Yüzey Araştırmaları IX. Antalya (2005) 131-147.

A. Erdoğan - M. R. Tunç, "Manavgat Irmağı ve Karpuz Çayı Çevresinin Kuş Türleri Üzerine Araştırmalar". XIV. Ulusal Biyoloji Kogresi 7-10 Eylül 1998, Samsun. Cilt 3 (1998) 169-180.

A. Erdoğan, H. Sert - M. R. Tunç, "Finike ve Çevresinin Kuş Faunası". Tabiat ve Insan 36/1 (2002) 30-40.

A. Erdoğan, M. Öz, H. Sert - M. R. Tunç, "Antalya Yamansaz Gölü ve Yakın Çevresinin Avifaunası ve Herpetofaunası". Ekoloji Çevre Dergisi 10/43 (2002) 33-39.

A. Erdoğan, A. Aslan, H. Sert, T. Albayrak - M. R. Tunç, Boğazkent Kocagöl ve Çevresi Kuş Envanteri Hazırlama Projesi. Boğazkent Belediyesi Sonuç Raporu (2002) 251.

A. Erdoğan, H. Sert, R. Vohwinkel, W. Prunte, T. Albayrak, A. Aslan - M. R. Tunç, "Manavgat/Titreyengöl Kuş Halkalama Çalışmaları". Tabiat ve insan 37/1 (2003) 19-25.

A. Erdoğan, M. Öz, M. R. Tunç, T. Albayrak, A. Aslan - H. Sert, Demre (Kale) "Noel Baba Kuş Cenneti" Kuşları. Antalya 2004.

A. Erdoğan, M. Öz, M. R. Tunç, H. Sert - M. Yavuz, Arkeolojisi, Tarihi, Doğası ve Tarımıyla Kumluca Rhodiapolis. Antalya 2008.

A. Erdoğan, M. R. Tunç, T. Albayrak - H. Karaardıç, "Kuşlar". Ed. H. Uğurluay, Türkiye'nin Doğa Rehberi. İstanbul (2010) 618-758.

A. Erdoğan, M. Öz, M. Yavuz, M. R. Tunç - H. Karaardıç, Arkeolojisinden Doğasına Myra/Demre ve Çevresi. Antalya 2010.

M. F. Heath - M. I. Evans, Important Bird Areas in Europe: Priority Sites for Conservation. 2 vols. Cambridge, UK 2000.

H. Heinzel, R. Fitter - J. Parslow, Pareys Vogelbuch. Alle Vogel Europas, Nordafrikas und mittleren Ostens. Hamburg und Berlin 1996.

H. Heinzel, R. Fitter - J. Parslow, Türkiye ve Avrupa'nın Kuşları. Trans.: K. A. Boyla. Anonymus 2001.

The IUCN Red List of Threatened Species Source: www.iucnredlist.org 2017-2 ISSN 2307-8235.

L. Jonsson, Birds of Europe, with North Africa and the Middle East. Belgium 1992.

H. Karaardıç, A. Erdoğan, R. Vohwinkel - W. Pruente, "The Relationship between Biometry and Migration Time among Nine Species of Warblers in Southern Turkey". Journal of Ornithology 147/5 (2006) 191.

H. Karaardıç, A. Erdoğan, R. Vohwinkel, W. Pruente - L. Özkan Karaardıç, New Records for West Turkey from Titreyengöl/Manavgat (Turkey) Ringing Study. $2^{\text {nd }}$ International Eurasian Ornithology Congress. 26-29 October 2007. Antalya (2007) 76.

H. Karaardıç, F. Köse - A. E. Tuna, "Gizli Cennet-Adrasan Kuşları". Tabiat ve insan 196 (2016) 25-35. 
Kirwan et al. 1998

Kiziroğlu 1987

Kiziroğlu 1989

Kiziroğlu 2008.

Kiziroğlu 2009

Kiziroğlu et al. 1992

Martins 1989

Mullarney 1999

Roselaar 1995

Sert - Erdoğan 2004

Svensson et al. 2010

Turan et al. 1998

Yarar et al. 1997

Yavuz - Tunç 2015a

Yavuz - Tunç 2015b
G. M. Kirwan, R. P. Martins, G. Eken - P. Davidson, "A Checklist of the Birds of Turkey". Sandgrouse Suppl.1/1 (1998) 32.

i. Kiziroğlu, The Birds of Turkey (Species List in Red Data Book). Ankara 1987.

i. Kiziroğlu, Türkiye Kuşları. Ankara 1989.

i. Kiziroğlu, Türkiye Kuşları Kırmızı Listesi. Ankara 2008.

i. Kiziroğlu, Türkiye Kuşları Cep Kitabı. Ankara 2009.

i. Kiziroğlu, L. Turan - A. Erdoğan, "Sultansazlığı'nın Eko-Ornitolojisi ve Son Durumu”. H.Ü. Eğitim Fakültesi Dergisi 7 (1992) 217-227.

R. P. Martins, "Turkey Bird Report 1982-6". Sandgrouse 11 (1989) 1-41.

K. Mullarney, L. Svensson, D. Zetterström - P. J. Grand, Collins Bird Guide. London 1999.

C. S. Roselaar, Songbirds of Turkey. An Atlas of Biodiversity of Turkish Passerine Birds. Haarlem 1995.

H. Sert - A. Erdoğan, "The Avifauna Researc Of Termesos National Park (Antalya-Turkey)". Turkish Journal of Zoology 28 (2004) 135-143.

L. Svensson, D. Zetterström - K. Mullarney, Birds of Europe: (Second Edition). Princeton 2010.

L. Turan - A. Erdoğan, "Avifauna Research of Antalya/Kurşunlu Redpine Natural Forest". Ornithologischer Anzeiger 37 (1998) 141-148.

M. Yarar - G. Magnin, Türkiye' nin Önemli Kuş Alanları. İstanbul 1997.

M. Yavuz - M. R. Tunç, "Phaselis Antik Kenti ve Yakın Çevresinin Faunası I". Phaselis I (2015) 143-183.

M. Yavuz - M. R. Tunç, "Fauna”. Ed. T. Korkut, Arkeoloji, Epigrafi, Jeoloji, Doğal ve Kültürel Peyzaj Yapısıyla Tlos Antik Kenti ve Teritoryumu. Ankara 2015. 